\title{
La poesía como un preludio a la filosofía: algunas reflexiones sobre un poema tardío de Borges
}

\author{
DOUGLAS MCDERMID \\ Department of Philosophy \\ Trent University \\ dmcdermi@trentu.ca
}

Resumen: En este artículo me propongo analizar un poema breve de Borges y relacionarlo con una idea metafilosófica de Platón; a saber, que la filosofía empieza con el asombro. Mi tesis fundamental es que hay poemas - y, en mi opinión, los versos de Borges que discutiré constituyen un ejemplo admirable-que pueden funcionar como un preludio a la filosofía en la medida en que pueden despertar el asombro platónico en los lectores capaces de experimentarlo.

Palabras clave: metafilosofía, el yo, posibilidad, costumbre

\begin{abstract}
In this essay I propose not only to analyze a poem by Jorge Luis Borges, but also to connect that poem with a metaphilosophical idea of Plato's — namely, the view that philosophy begins in wonder. For I argue that some poetry - Borges' brief poem being an admirable example- can serve as a prelude to philosophy by arousing Platonic wonder in readers capable of experiencing it.
\end{abstract}

Key words: metaphilosophy, the self, possibility, custom

[Muchas personas] dan por supuesto el universo. Dan todo por supuesto. Incluso se dan por supuesto ellos mismos. Es así. Jamás se preguntan nada, ¿verdad? No piensan que sea extraño el hecho de vivir.

JORGE LUIS BORGES ${ }^{1}$

Mas aún, ¿qué es la filosofía en su totalidad, sino una batalla continua contra la Costumbre, un esfuerzo constantemente renovado por trascender la esfera de la ciega Costumbre, y así convertirse en Trascendental?

THOMAS CARLYLE ${ }^{2}$

El más grande de los poemas es un inventario.

G.K. Chesterton ${ }^{3}$

${ }^{1}$ Burgin 1974, p. 29. Ésa es la respuesta de Borges a una observación hecha por su interlocutor, Richard Burgin, quien comentó que la mayoría de las personas no piensan en los acertijos metafísicos que han significado tanto para Borges.

${ }^{2}$ Carlyle 1987 (1834), p. 98: "Nay, what is Philosophy throughout but a continual battle against Custom; an ever-renewed effort to transcend the sphere of blind Custom, and so become Transcendental?"

${ }^{3}$ Chesterton 1957 (1908), p. 99 "The greatest of poems is an inventory." 


\section{Introducción}

Yo, desgraciadamente, no soy la excepción. Como otros filósofos con "un apetito por la poesía", ${ }^{4}$ soy plenamente consciente del pleito antiguo entre la poesía y la filosofía — un pleito ya viejo en tiempos de Platón-, y releer los juicios cáusticos de Sócrates sobre los intérpretes de la poesía me pone siempre a la defensiva, haciéndome sentir a la vez molesto y vagamente avergonzado. ${ }^{5}$ Por lo tanto, es con algo de ansiedad y de inquietud (si no precisamente con temor y temblor) que aquí me propongo analizar un poema de Borges y relacionarlo con una idea metafilosófica del propio Platón; a saber, que la filosofía empieza con el asombro. ${ }^{6} \mathrm{Mi}$ tesis fundamental es que hay poemas - y, en mi opinión, los versos de Borges que discutiré constituyen un ejemplo admirable- que pueden funcionar como un preludio a la filosofía, en la medida en que pueden despertar el asombro platónico en los lectores capaces de experimentarlo.

Mi ensayo se divide en cinco partes. Tras introducir el poema de Borges y hacer algunas observaciones preliminares sobre su forma y el lugar que ocupa en su obra (§§ 2-4), ofrezco una lectura del poema como una meditación sobre la contingencia radical (más específicamente, la contingencia triple del mundo, de la identidad y del lenguaje) (§§ 5-7). En seguida describo cómo el reconocimiento y la asimilación imaginativa de dicha contingencia pueden conducir a la experiencia del asombro que, según Platón y Schopenhauer, es la fuente verdadera de la filosofía (§§ 8-11). Tras responder a unas objeciones ( $\S 12$ ), finalizo, sin disculpas ni excusas, con una conclusión aparentemente irresponsable y perversa $(\S 13)$.

\section{El poema}

El breve poema de Borges que quiero discutir tiene título en inglés: "Things That Might Have Been". He aquí el poema:

Pienso en las cosas que pudieron ser y no fueron.

El tratado de mitología sajona que Beda no escribió.

La obra inconcebible que a Dante le fue dada acaso entrever,

Ya corregido el último verso de la Comedia.

\footnotetext{
${ }^{4}$ Le debo esa frase a Kermode (1989), quien se la debe a Paul Valéry.

${ }^{5}$ Véase República 607B; Protágoras 347C-348B.

${ }^{6}$ Confieso, además, que mis ansiedades sólo crecen al pensar en los riesgos peculiares que tienen que enfrentar esas almas temerarias que, en su inocencia o su vanidad, pretenden contribuir a la literatura secundaria sobre Borges. No diré más sobre esos llamados "gajes del oficio", mas el lector ocioso e inquisitivo puede consultar el ensayo perspicaz de Alejandro Rossi, "La página perfecta" (Rossi 1986, pp. 18-23). Véase el cap. 13 de la novela Doctor Criminale de Malcolm Bradbury (1992).
} 
La historia sin la tarde de la Cruz y la tarde de la cicuta.

La historia sin el rostro de Helena.

El hombre sin los ojos, que nos han deparado la luna.

En las tres jornadas de Gettysburg la victoria del Sur.

El amor que no compartimos.

El dilatado imperio que los Vikings no quisieron fundar.

El orbe sin la rueda o sin la rosa.

El juicio de John Donne sobre Shakespeare.

El otro cuerno del Unicornio.

El ave fabulosa de Irlanda, que está en dos lugares a un tiempo.

El hijo que no tuve. ${ }^{7}$

Quiero empezar mi análisis con dos observaciones. La primera de ellas versa sobre el género del poema ( $\S 3$ ), mientras que la segunda avanza una clasificación provisoria y tentativa de las posibilidades no realizadas que el poema nombra e incorpora (§ 4).

\section{Sobre poemas y catálogos}

Cabe destacar que "Things That Might Have Been" pertenece a un género poético al que Borges fue adicto: el poema en la forma de un catálogo. Este tipo de poema — podemos denominarlo "el poema-catálogo" (para la satisfacción de aquellos a los que les gusta usar terminología pomposa aun para cosas familiares) - tiene dos elementos principales. Primero, hay un conjunto extraño de cosas dispares, una lista de amplitud impresionante sin signos obvios de coherencia o unidad interna; segundo, hay una afirmación de que, no obstante la apariencia de una pluralidad caótica e irreducible, hay una categoría unificadora, o una clase a la cual todas esas cosas heterogéneas pertenecen. En muchos de los poemas-catálogos escritos por Borges - "Las cosas", "Cosas", "Talismanes", "Las causas", "El hacedor", "Poema" y "Los justos" son ejemplos notables_ ${ }^{8}$ la clase relevante sólo se identifica o se especifica en las últimas líneas, tras haber revisado la lista en su totalidad. En "Things That Might Have Been", en cambio, el orden se invierte: empezamos explícitamente con la categoría unificadora ("cosas que pudieron ser y no fueron"), y entonces procedemos a leer el catálogo de artículos diversos que caen bajo esa categoría. Aunque este modo de presentación elimina el elemento de suspenso taxonómico -el lector sabe,

${ }^{7}$ Se encuentra en la colección Historia de la noche; véase Borges, Obras completas (en adelante, $O C$ seguido del volumen en números romanos), vol. III, p. 189.

${ }^{8}$ Véase Borges 1996, vol. II, pp. 370, 481-482, y OC III, pp. 111, 199, 311, 319, 326. 
desde el principio, lo que los miembros de la lista supuestamente tienen en común - también posibilita una conclusión conmovedora, en la cual las abstracciones y los conceptos dan lugar a lo particular, lo concreto y lo personal.

\section{Catalogando un catálogo}

Dejando a un lado la cuestión del género poético, pasemos ahora a examinar el catálogo que el poema presenta. He aquí una manera en la cual se pueden subclasificar o categorizar las "cosas que pudieron ser y no fueron": 9

(i) Obras literarias: "el tratado de mitología sajona que Beda no escribió" (2); "[l]a obra inconcebible" de Dante (3); "[e]l juicio de John Donne sobre Shakespeare" (12);

(ii) Sucesos de importancia mayor en la historia mundial: "[1]a historia sin la tarde de la Cruz y la tarde de la cicuta" (5); "[1]a historia sin el rostro de Helena" (6); "[e]n las tres jornadas de Gettysburg la victoria del Sur" (8); [e]l dilatado imperio que los Vikings no quisieron fundar" (10);

(iii) Objetos en el mundo de la naturaleza: "[e]1 hombre sin los ojos, que nos han deparado la luna" (7), "[e]l orbe [...] sin la rosa" (11);

(iv) Bestias imaginarias o criaturas mitológicas: "[e]1 otro cuerno del Unicornio" (13); "[e]l ave fabulosa de Irlanda, que está en dos lugares al mismo tiempo" (14);

(v) Invenciones tecnológicas:: "[e]l orbe sin la rueda" (11); y, finalmente,

(vi) Episodios pertenecientes a la vida íntima de Borges: "[e]l amor que no compartimos" (9); “[e]l hijo que no tuve" (15).

Vale la pena hacer dos observaciones breves acerca de la lista y su contenido:

En primer lugar, la actitud del poeta frente a algunas de las posibilidades no realizadas - las llamadas "cosas que pudieron ser y no fueron"- no carece de cierta ambigüedad, pues no siempre es fácil saber — sobre todo en el caso de los artículos incluidos en (vi)— si se siente arrepentimiento (por una oportunidad perdida), alivio (por haber eludido lo que hubiera sido una catástrofe), una curiosidad más o menos académica o especulativa, o enteramente otra cosa.

${ }^{9}$ Ofrezco lo que sigue sólo como un esquema clasificatorio entre otros; como nos dice "El idioma analítico de John Wilkins" (OC II, pp. 84-87), siempre hay una pluralidad de maneras de organizar lo dado. 
En segundo lugar, se debe notar — de hecho, es imposible no hacerlola diversidad de los tipos de cosas y entidades que el poema abarca y enumera: libros y flores, guerras y amores, ejecuciones e innovaciones, seres naturales e imaginarios; todos encuentran un lugar en ese inventario rarísimo al que nos enfrentamos. De allí una pregunta: ¿se debe inferir que el catálogo es realmente un mero revoltijo confuso, es decir, una colección absurda de cosas que no tienen nada en común salvo la distinción, a la vez mínima y dudosa, de nunca haber existido? De ninguna manera, diría yo; mas para hacerle justicia a la postura implícita en mi respuesta tendré que esbozar una interpretación del poema.

\section{De la Cruz y de la cicuta}

Como su título indica, "Things That Might Have Been" nos recuerda que lo posible excede a lo actual. Pero el punto aquí no es meramente que el mundo pudo haber sido distinto; es que el mundo pudo haber sido radicalmente distinto muy fácilmente, pues la realidad que nos refleja el poema es una convergencia delicada e inestable de contingencias, la cual depende en gran medida de minucias que aparentemente carecen de importancia: dos tardes, tres días, un rostro, unos ojos, un orbe, una flor, un hijo, etc. $\mathrm{Al}$ recordarnos la absurda falta de proporción entre las causas triviales y sus efectos trascendentales, Borges retoma un tema asociado con Pascal, cuyo celebrado aperçu - "La nariz de Cleopatra: si hubiese sido más corta, toda la faz de la tierra habría cambiado"- ${ }^{10}$ encuentra un eco resonante en la alusión borgesiana a la posibilidad de "la historia sin el rostro de Helena" (6).

Para profundizar nuestro aprecio de la manera sutil e ingeniosa en la que Borges desarrolla el tema de la contingencia radical basta con examinar uno de los artículos más provocadores de su catálogo: la invitación a pensar en "la historia sin la tarde de la Cruz y la de la cicuta" (5). Se notará de inmediato que Borges se abstiene de referirse explícitamente a Sócrates o a Jesús. ¿Por qué esa omisión? Podemos suponer que se debe a que no hace falta invocar sus nombres una vez que hayamos mencionado sus fines, puesto que sus muertes deben verse como expresiones esenciales o definitivas de sus identidades respectivas. ${ }^{11}$ Un Sócrates nunca condenado a la muerte por los atenienses no sería Sócrates, aunque fuera un mampostero feo, esposo de la arpía Xantipa, amigo del decadente Alcibíades, ex alumno distinguido de Diotima, instigador de innumerables discusiones filosóficas,

\footnotetext{
10 "La nez de Cléopâtre: s'il eût été plus court, toute la face de la terre aurait changé" (Pensées, 162).

${ }^{11}$ Esa idea - la de que la disposición de una persona a elegir y aceptar una manera particular de morir puede revelar o hacer su identidad-se podría utilizar para entender la decisión tomada por Juan Dahlmann al final del estupendo cuento "El Sur" (OC I, pp. 524-529).
} 
etc. De la misma manera, un Jesús no crucificado no sería el personaje que la gente reconocería como Jesús, aunque fuera un hombre de Galilea, hijo de una mujer llamada María, un predicador carismático con discípulos y seguidores, autor del Sermón de la Montaña y algunas parábolas, etcétera.

Digamos, entonces, que Borges está insinuando que no hay Sócrates sin la cicuta; y que sin la Cruz, no hay Jesús. Pero sin estos dos personajes, lo que llamamos la historia hubiera sido muy diferente, y eso implica, a su vez, que nosotros, como seres formados por dicha historia, seríamos criaturas distintas e incluso irreconocibles, ya que nuestras actitudes hacia los ideales representados por Sócrates y Jesús han llegado a ser partes integrales de nosotros, casi como "los ojos [...] que nos han deparado la luna" (7). ${ }^{12}$ En otras palabras: puesto que el yo está profundamente condicionado e informado por el mundo y su historia, el descubrimiento de que la historia y el mundo podrían haber sido distintos lleva consigo la revelación vertiginosa de que la identidad actual de una persona es sólo una de innumerables identidades posibles. Así es que Borges hubiera sido una persona diferente - $-\mathrm{y}$, por lo tanto, no "Borges"- ${ }^{13}$ si no hubieran existido Sócrates o Jesús, la Iliada o la Odisea; si él hubiera leído las obras que Beda, Dante y Donne nunca escribieron; si él hubiera compartido el amor con la persona que el poema no se atreve a nombrar; si él hubiera sido un padre; etc. (Aquí la locución "etcétera" es tan torpe como inevitable, ya que no hay, ni puede haber, un límite o un fin a la lista.)

\section{6. "I've Got a Little List. .."14}

Tomando en cuenta lo anterior, ahora podemos regresar a la pregunta planteada al final de $\S 4$ : ¿cómo se debe entender el carácter extremadamente heterogéneo y aparentemente arbitrario del catálogo? Un dilema se nos presenta de inmediato. Por un lado, es evidente que la lista es absurdamente breve como para constituir un inventario exhaustivo o global de todas las "cosas que pudieron ser y no fueron" (asumiendo, per impossibile, que tal proyecto fuera viable). Por el otro lado, la lista es demasiado peculiar e idiosincrásica como para constituir una lista selectiva de las cosas juzgadas como las más importantes o significativas "que pudieron ser y no fueron" desde una perspectiva humana pero absolutamente imparcial u objetiva (si es que la hubiera). En consecuencia, hay una pregunta inevitable que ahora tenemos que enfrentar: ¿por qué esta lista y no otra?

\footnotetext{
${ }^{12}$ Para que no se me reproche aquí inútilmente - los reproches útiles son bienvenidos, por supuesto- me gustaría enfatizar que me refiero no a los ideales, sino a nuestras actitudes frente a ellos. Así, pues, aun la gente más hostil a los ideales representados por Sócrates o Jesús - los nietzscheanos convencidos, por ejemplo- podrían estar de acuerdo con esa observación sin ser infieles a sus principios.

13 Véase "Borges y Yo" (OC II, p. 186).

14 "Tengo una pequeña lista..." Véase W.S. Gilbert y A. Sullivan, The Mikado, acto I.
} 
Porque ésta es la lista de Borges; como una especie de antología personal, su contenido refleja las manías y las excentricidades, los deseos y los gustos, las aptitudes y las limitaciones, las percepciones y la ceguera de un individuo particular, viviendo en una civilización particular en una época particular. En otras palabras, podemos tomar el catálogo como una expresión parcial de la individualidad irreemplazable de Borges; podemos suponer que nadie lo podría haber escrito salvo él. Pero nota bene: eso implica que si no hubiera jamás existido Borges —una suposición melancólica, desde luego, pero perfectamente posible-, no existiría este poema; o, más bien, a lo mejor sólo podría tener una existencia tenue como un artículo en otro inventario, una línea en el poema de otro poeta. Por ejemplo:

\section{Things That Might Have Been}

Pienso en las cosas que no fueron, pero que pudieron ser:

La ficción, sin la ficción

de un lector ejemplar

nacido con el nombre de Quijano.

Las bibliotecas, sin la biblioteca vacía

donde un vasco herido en vano buscó

aventuras profanas de Amadís...

Un poema, mucho mejor que el mío,

que comparte su título y que hubiera escrito

un genio hipotético jamás nacido. ${ }^{15}$

Por ende, el poema de Borges se ubica como un objeto dentro del mismo campo que su catálogo explora selectivamente: el dominio de lo contingente y lo posible, de lo frágil, de lo que existe pero no tiene que ser. El poema, en pocas palabras, es parte de lo que se trata; no lo puede evitar.

\section{El otro: Borges y Georgie}

La categoría de la contingencia es también la clave para responder a otra pregunta: ¿por qué el poema, compuesto en español, tiene un título en inglés? Estoy a favor de la explicación de que la frase "Things That Might Have Been" evoca la posibilidad de otro Borges, un alter ego o doppelgänger lingüístico, que escribió no en español sino en inglés. Como señala Emir Rodríguez Monegal en su biografía literaria de Borges, el joven "Georgie"

${ }^{15}$ Seguramente alguien tendrá la sospecha de que esas líneas vinieron de la pluma de un tal Danieri; sin embargo, les aseguro que esta vez él no tiene la culpa. 
(como solían llamar dentro del círculo íntimo de su familia) podría haber escrito en inglés (Rodríguez Monegal 1978, p. 19).

Es bien conocido, por ejemplo, que su abuela paterna, la formidable Fanny Haslam, era inglesa; que ella solía leer a su Georgie en su idioma natal; que Borges aprendió a leer primero en inglés y luego en español; que leyó Don Quijote por primera vez en una traducción inglesa; que, cuando finalmente leyó la obra de Cervantes en su versión original, se quejó, diciendo que se leía como si fuera una traducción mediocre; que el primer texto que escribió — se trataba de la mitología griega - fue compuesto en inglés; que su primera publicación (a los nueve años de edad) era una traducción de un cuento de Oscar Wilde ("The Happy Prince"); que, hasta los nueve años, fue educado por una institutriz británica, Miss Tink; y que pasó mucha de su juventud en Buenos Aires en la biblioteca de su padre, rodeado por libros escritos por autores británicos y estadounidenses. ${ }^{16}$

Así, pues, el título del poema no sólo ejemplifica el fenómeno que designa (en cuanto que la escritura de Borges en inglés nos señala una cosa más que pudo ser pero no fue); también hace hincapié en la contingencia del medio del poema, es decir, el lenguaje mismo. ${ }^{17}$ Para ser más preciso: el poema insinúa que el lenguaje es contingente por lo menos en tres sentidos: (1) Qué lenguaje(s) uno hereda y habita es un accidente, un asunto del azar. Lo que pasó con Borges se aplica también a cada uno de nosotros: como el joven George, en principio pudimos haber tenido otro lenguaje como nuestro idioma natal. Y este punto, bajo ciertas suposiciones acerca de la relación entre el yo y el lenguaje, nos regresa al tema de la contingencia de la identidad. ${ }^{18}$ (2) Más aún, los idiomas o lenguajes son creaciones mutables que tienen una historia. Evolucionando y cambiando, están hechos y rehechos; y sus recursos — las posibilidades expresivas y descriptivas que encarnan- se renuevan y aumentan gracias a aquellos que llamamos poetas. Pero si eso es cierto —si algunos poemas pueden cambiar o recrear un idioma-, es razonable suponer que los lenguajes y las tradiciones literarias serían notablemente diferentes, si ciertos poemas no existentes - "la obra inconcebible" de Dante (3), por ejemplo- hubieran sido escritos, o si algunos poemas monumentales - como los épicos homéricos, que presuponen "el rostro de Helena" (6) - no hubieran sido compuestos jamás. (3) Finalmente, la aparición del lenguaje - y las cosas

\footnotetext{
${ }^{16}$ Sobre la familia de Borges y su niñez bilingüe, véase Rodríguez Monegal 1978, partes I y II; cfr. Vaccaro 1996, partes I-V. Beatriz Sarlo (1995, pp. 95-96) resume los hechos básicos con una economía encomiable.

${ }^{17}$ Para más sobre la contingencia del lenguaje, véase Rorty 1989, cap. 1 . He discutido su entendimiento del lenguaje y su relación con el problema del escepticismo en McDermid 2000 y 2004.

${ }^{18}$ El bilingüe novelista francés Julien Green, nacido en París de padres estadounidenses, explora este tema; cfr. Green 1976, p. 98. Green describe su formación bilingüe en su obra de 1942, Memories of Happy Days.
} 
(como los poemas) en los que las prácticas y normas lingüísticas subyacen y a las que posibilitan - no era en absoluto inevitable. Dicho de otra manera, el lenguaje es un don; se puede concebir fácilmente - como otra cosa que pudo ser y no fue- un mundo donde no hubo nunca tal cosa (aunque, claro está, quien pueda describir un mundo sin lenguaje ipso facto no lo habita). ${ }^{19}$

\section{Recapitulación y anticipo}

Hasta ahora me he limitado a recomendar y promover una lectura determinada de "Things That Might Have Been", según la cual el poema versa sobre la contingencia y la posibilidad de lo subjuntivo. Lo que quiero hacer en el resto de este ensayo es explorar cómo el poema de Borges puede abrir para nosotros un camino a la filosofía. Mi exploración constará de dos etapas: primero explicaré cómo el ejercicio imaginativo de Borges puede producir el asombro (§ § 9-10); luego expondré brevemente la manera como Platón y Schopenhauer entendieron la relación entre el asombro y la filosofía (§ 11).

\section{La costumbre y el imperio de la banalidad}

Comencemos con un datum humilde pero en apariencia incontrovertible; a saber, que por lo general se da por sentado lo ordinario o lo cotidiano, justamente porque estamos acostumbrados a ello. Se ha dicho que la familiaridad suele producir el desdén; ${ }^{20}$ pero aquí lo que produce es más bien el equivalente epistemológico a la indiferencia, es decir, una falta de sensibilidad o una ceguera. El hecho es que no nos percatamos mucho de lo que nos rodea constantemente; la costumbre, como observó Montaigne, entorpece nuestras facultades de percepción. Por lo tanto, nuestra relación con el dominio de lo ordinario es tal que ni nos damos cuenta del hecho de que no lo percibimos con los ojos bien abiertos. De hecho, casi podríamos decir - pidiendo disculpas a Berkeley- que ser ordinario es no ser percibido. ${ }^{21}$

Pero cada vez que, debido a la familiaridad y a la repetición, algún fenómeno llega a ser común y corriente para nosotros, es decir, cada vez que la costumbre le confisca la originalidad a las cosas y destierra el asombro, las

\footnotetext{
${ }^{19}$ Esto recuerda un argumento infame a favor del idealismo que usan Berkeley y Schopenhauer; véase McDermid 2003 para unas observaciones críticas.

${ }^{20}$ Como se dice en inglés: "Familiarity breeds contempt."

${ }^{21}$ Se encuentra una ilustración excelente (y entretenida) de esa idea en "El hombre invisible" ("The Invisible Man"), un cuento policial de Chesterton, conocido por Borges (OC IV, p. 347). (Para la fórmula original del idealismo de Berkeley con que estoy jugando, véase Berkeley 1998 (1710), § 3.
} 
fronteras del imperio de lo banal se extienden. Así es que, en las palabras de Thomas Carlyle —o más bien en aquellas de su alter ego en Sartor Resartus, el filósofo de la ropa Diogenes Teufelsdröckh—: "La Costumbre nos convierte a todos en viejos seniles." ${ }^{22}$ Según Teufelsdröckh-Carlyle,

Son innumerables los trucos ilusionistas de la Costumbre: pero de entre todos ellos quizá el más ingenioso es su habilidad para convencernos de que lo Milagroso, por simple repetición deja de ser Milagroso. Claro está, sin ella no podríamos vivir; pues el hombre debe trabajar, además de asombrarse: y hasta aquí y en este sentido la Costumbre es una niñera bondadosa que lo guía hacia su verdadero beneficio. Mas se trata de una niñera tonta, o más bien somos pacientes tontos y falsos cuando, en nuestras horas de descanso y reposo, prolongamos la misma decepción. ¿Debo ver lo Estupendo con indiferencia estúpida porque lo he visto dos, doscientas o dos millones de veces? ${ }^{23}$

No obstante su tono bombástico y grandilocuente, este pasaje expresa una actitud equilibrada frente a la costumbre; pues Carlyle, como Montaigne, representa la costumbre como una fuerza potencialmente benévola (a kind nurse) y perniciosa (a foolish nurse); es decir, como algo indispensable para la actividad práctica y el trabajo (by this means we live), y como una fuente de ilusiones, distorsiones y falsedades (legerdemain tricks) que confunde o pervierte nuestro entendimiento. ${ }^{24}$ Además, se debe observar que aunque lo que en realidad le preocupa al idealista Teufelsdröckh en el párrafo citado es la idea de que nuestra percepción de la Naturaleza (i.e. el reino de las apariencias o los fenómenos kantianos) se podría falsificar gracias al velo

22 "Custom doth make dotards of us all" (Carlyle 1987 (1834), p. 196); cfr. Hamlet III, i, 90. Borges escribió un prólogo a Sartor Resartus (OC IV, pp. 35-36), un libro que utiliza una idea borgesiana: la de hacer un comentario sobre un libro recherché y no escrito. Véase la referencia a Sartor Resartus en el prólogo a El jardín de senderos que se bifurcan (1941) (OC I, p. 429).

${ }^{23}$ Carlyle 1987 (1834), p. 196: "Innumerable are the illusions and legerdemain tricks of Custom: but of all these perhaps the cleverest is her knack of persuading us that the Miraculous, by simple repetition, ceases to be Miraculous. True, it is by this means we live; for man must work as well as wonder: and herein is Custom so far a kind nurse, guiding him to his true benefit. But she is a foolish nurse, or rather we are false foolish nurselings, when, in our resting and reflecting hours, we prolong the same deception. Am I to view the Stupendous with stupid indifference because I have seen it twice, or two hundred, or two million times?"

${ }^{24}$ Aquellos pensadores que no valoran la actividad práctica y el trabajo como lo hace Carlyle pueden ver la costumbre en una manera tendenciosa, representándola principalmente como un estorbo o una mera fuente de prejuicios. Un buen ejemplo sería Walter Pater, cuyo veredicto peyorativo sobre la costumbre - "nuestro fracaso es formar hábitos" ("our failure is to form habits") (Pater 1986 (1873), p. 152) - es un corolario de su esteticismo, según el cual debemos cultivar nuestras capacidades como observadores atentos, exquisitamente sensibles a los matices sutiles de nuestra experiencia. Para más sobre el esteticismo y sus variedades, véase Pereda 1998, parte I. 
tejido por la costumbre, su preocupación básica acerca del poder negativo de la costumbre puede extenderse. Ya que son muchas las cosas cuya naturaleza está escondida u oculta por la costumbre: conciencia, lenguaje, conocimiento, ciencia, religión, arte, historia, mitos, moralidad, tradiciones, instituciones, convenciones (incluyendo la ropa que le fascinaba tanto a Teufelsdröckh) ${ }^{25}$ y muchas más, incluyendo la costumbre misma. (Siento la tentación casi irresistible de añadir "etcétera", puesto que no sería nada fácil terminar esta lista.) Colonizados por la costumbre, anexados por el uso prolongado y el hábito, esas cosas pueden sin dificultad dejar de pertenecer a la república de lo "estupendo" y llegar a ser simplemente las posesiones de la banalidad.

Pero si bien es cierto que el dominio de lo cotidiano ha sido invadido y ocupado por las fuerzas de la banalidad, no se debe olvidar que los poetas como Borges forman parte de un movimiento de resistencia metafísica (por decirlo así). Pues en la medida en que "Things That Might Have Been" inicia una liberación de lo ordinario ( $\mathrm{y}$ en un sentido un redescubrimiento de ello) a través del acto de imaginar alternativas a lo familiar, el poema se puede interpretar como un intento ingenioso de resistir y detener el proceso de banalización lamentado por Carlyle. Permítaseme explicar esto.

\section{El asombro y el reconocimiento de la contingencia}

Sin duda, la idea de que podemos enfrentar la actualidad ignorándola y pensando en lo contrario - lo meramente posible - tiene un aire paradójico. Pero al desprendernos de lo familiar y lo ordinario, el reconocimiento imaginativo de ausencias y posibilidades no actualizadas puede cambiar nuestra relación con lo actual y lo presente, modificando nuestra perspectiva y ofreciéndonos la distancia requerida para ver esas cosas por primera vez. Por primera vez, digo, porque parece innegable que la costumbre nos impide ver los fenómenos más familiares y cercanos; invisible como el aire, el esquema que comprende lo que se da por hecho constituye un fondo, ${ }^{26}$ un marco fijo de referencia que funciona como una condición de la posibilidad de percepción (entendida aquí como la detección de novedades salientes). Pero la confrontación con lo subjuntivo arreglada por Borges deshace - si bien sólo momentáneamente- el efecto anestésico de la repetición; tras haber revisado el catálogo de su poema, nos quedamos atónitos por el hecho de que ningún elemento en nuestro marco de referencia se puede dar por hecho. Ahora las cosas mundanas y cotidianas a las que

${ }^{25}$ Y a Umberto Eco también; véase su ensayo encantador, "Lumbar Thought" (Eco 1986, pp. 191-195).

${ }^{26}$ La idea de un marco fundamental que subyace en compromisos particulares se encuentra en el segundo Wittgenstein (1969); véase Strawson 1985, cap. 1. 
estamos acostumbrados -incluyendo, desde luego, nuestra propia identidad, nuestro mundo y nuestro lenguaje- se pueden ver no como cosas dadas, preordinadas o inevitables, sino como entidades precarias, gratuitas y frágiles; cosas que fácilmente pudieron no ser. ${ }^{27}$

Expuestos directamente al carácter gratuito y aleatorio de lo que siempre hemos dado por sentado, podemos experimentar una sensación incómoda - como una especie de vértigo o mareo, parecida a la nausée de Sartre $-{ }^{28}$ al contemplar algunos de los escenarios alternativos de Borges. No obstante que perdimos la inocencia en un nivel -a saber, en el de una serena y ciega aceptación de lo ordinario-, hay otro nivel en el cual podemos recuperarla. Ya terminado nuestro largo sueño dogmático, empezamos a plantear preguntas que encarnan nuestra perplejidad y expresan la ignorancia implícita en ella: "¿por qué existe precisamente este conjunto de cosas, y no otro?; ¿hasta qué punto sería diferente el mundo (o yo) si tan sólo...?" Y una vez que se haya efectuado este cambio lingüístico desde lo subjuntivo hacia lo interrogativo, es decir, una vez que nos hayamos desprendido de nuestro esquema y quedemos confundidos por las cosas comunes y corrientes, estaremos volviendo del exilio y camino a casa, desde la banalidad y hacia el asombro.

\section{El nacimiento de la filosofía por el espíritu del asombro}

"Está muy bien todo eso", nos diría nuestro crítico filosófico, con desdén e impaciencia, "pero ¿a dónde nos lleva? ¿Cuáles son las implicaciones?"

Aquí se debe recordar que esa criatura nacida en la tarde de la cicuta, el maestro y portavoz de Platón, insistió en que la filosofía empieza con el asombro; de hecho, afirma que el sentido de lo asombroso es el signo del filósofo (Teeteto 155d). Esa misma intuición —la de que uno no puede filosofar hasta no sentirse perplejo y confundido por lo que los demás, presos del sentido común, dan por hecho- también se encuentra en otros autores; ${ }^{29}$ y quizá recibió una de sus formulaciones más elocuentes y memorables en las páginas de uno de los filósofos preferidos del propio Borges. Me refiero, desde luego, a Schopenhauer, ${ }^{30}$ en cuya obra maestra Die Welt als Wille und Vorstellung se lee:

${ }^{27}$ Aquí viene al caso citar algo sobre el mismo tema escrito por un autor estimado por Borges; cfr. Chesterton 1957 (1908), p. 100. Una presentación más reciente de la misma idea se encuentra en Nagel 1986, pp. 211-212.

${ }^{28} \mathrm{O}$ la sensación igualmente desagradable experimentada por el narrador en "Terror", un cuento de Nabokov (2002, pp. 173-178).

${ }^{29}$ Cabe señalar, por ejemplo, que esa idea ha desempeñado un papel prominente en las obras de autores afiliados de algún modo a la tradición escéptica: Pirro, Montaigne, Descartes, Pascal y Hume (para mencionar sólo algunos).

${ }^{30}$ Sobre la recepción de Schopenhauer por Borges, véase Rodríguez Monegal 1978, pp. 139-140. El libro de Nuño Montes, La filosofía de Borges (1986), contiene una discusión 
Por otra parte, la disposición filosófica propiamente hablando consiste especialmente en nuestra capacidad de experimentar asombro ante los lugares comunes de ocurrencia diaria, la cual nos lleva a reflexionar sobre lo universal del fenómeno. Investigadores en las ciencias físicas, en cambio, se maravillan sólo ante fenómenos raros y selectos y su problema es relacionarlos con fenómenos mejor conocidos. La existencia misma resulta menos desconcertante y misteriosa para un hombre con menor desarrollo intelectual. Por el contrario, todo en cuanto a cómo es, y en cuanto a qué es, lo da por sentado. ${ }^{31}$

¿La moraleja? Podemos expresarla en una forma condicional: si Platón y Schopenhauer tienen razón, entonces un poema que genera el asombro nos puede poner en el camino a la filosofía. Mas soy consciente de que esa manera de expresar este asunto tal vez parezca demasiado figurada e imprecisa; en consecuencia, para el beneficio de gente con un enfoque prosaico - como los que enloquecen por términos sonoros como "poemacatálogo"-, quiero añadir una reconstrucción más rigurosa y lúcida. Lo esencial del argumento podría resumirse así: (i) si el asombro es la fuente de la filosofía auténtica, entonces no puede haber filosofía digna de ese nombre sin el sentimiento del asombro; (ii) el poema de Borges puede inspirar el asombro; por lo tanto, (iii) el poema de Borges satisface una de las condiciones necesarias para la reflexión filosófica. Por ende, (iv) si la filosofía es posible sólo cuando hay el estímulo del asombro, entonces algunos poemas pueden prepararnos para el pensamiento filosófico, puesto que satisfacen una condición sine qua non de su posibilidad.

Entonces, si estamos de acuerdo con Platón y con Schopenhauer por lo que mira al origen de la filosofía, podemos afirmar que la poesía y la filosofía no están siempre en oposición y enfrentadas como si fueran enemigas incansables involucradas en una lucha perpetua. Aunque la filosofía y la poesía estén destinadas a pelearse hasta con amargura, rencor y desprecio mutuo, puede haber momentos en los cuales se suspendan las hostilidades y se declare una tregua, momentos extraños en los que escuchar la voz de

interesante de la influencia de la tradición idealista (especialmente Schopenhauer y Berkeley) en la obra de Borges.

${ }^{31}$ Sämtliche Werke, II: XVII, 207: "Auch besteht die eigentliche philosophische Anlage zunächst darin, daß man über das Gewöhnliche und Alltägliche sind zu verwundern fähig ist, wodurch man eben veranlaßt wird, das Allgemeine der Erscheinung zu seinem Problem zu machen; während die Forscher in den Realwissenschaften sich nur über ausgesuchte und seltene Erscheinungen verwundern und ihr Problem bloß ist, diese auf bekanntere zurückzuführen. Je niedriger ein Mensch in intellektueller Hinsicht steht, desto weniger Rätselhaftes hat für ihn das Dasein selbst: ihm scheint vielmehr sich alles, wie es ist und daß es sei, von selbst zu verstehn." Diría que esa tendencia de fundamentar la reflexión filosófica en el asombro se puede ver en la réplica de Schopenhauer al escepticismo y en sus argumentos a favor del idealismo trascendental (cfr. McDermid 2002 y 2003). 
la poesía nos puede llevar a esperar, y luego a prestar atención, a la voz de la filosofía. ${ }^{32}$

\section{Quaestiones disputate: objeciones y respuestas}

Para aclarar mi postura, me gustaría evaluar cuatro objeciones en una forma pseudoescolástica:

Objeción 1: "Se ha dicho que los versos de Borges pueden producir el asombro. Pero virtualmente cualquier cosa puede hacer esto (e.g. el mole poblano, el sonido del mar, un ramo de bugambilia, un gesto, etcétera)."

Respuesta: Desde luego —y no quiero subestimar la significación metafísica del mole poblano-; pero mi postura no es que el poema de Borges sea el único objeto con la capacidad de inspirar o producir el sentimiento de asombro. Al contrario: mi lectura del poema presupone tal hecho, ya que sostengo que las palabras de Borges revelan el asombro inherente en varias cosas familiares y cotidianas. Por lo tanto, el mero hecho de que son muchas las cosas con esa capacidad no es ningún argumento en contra de la interpretación de "Things That Might Have Been" que he propuesto.

Aunque no me parece contundente esa primera crítica, tal vez sea posible, e incluso aconsejable, buscar otra formulación de la intuición básica que se encuentra detrás de la objeción 1 . Consideremos ahora la siguiente versión:

Objeción 2: "Pero si se admite que todas las cosas pueden funcionar como fuentes del asombro, entonces parece que tendremos que confesar que el poema de Borges no es nada extraordinario y que carece de distinción."

Respuesta: Si bien es cierto que cualquier cosa puede producir en nosotros el asombro, y que de ello se sigue que el poema no es extraordinario en ese respecto (i.e. que no es la única entidad con esa propiedad), no se puede sacar la conclusión de que no hay nada especial en el poema. Aceptar esa inferencia falaz sería como si uno sacara la conclusión de que todos los hombres altos son iguales o idénticos sans phrase, ya que, desde luego, todos son altos. Por consiguiente, no hemos impugnado los méritos estéticos del poema; no tenemos que negar que "Things That Might Have Been" sea un logro creativo sobresaliente (y lo es, en mi opinión).

Objeción 3: "Mas los versos de Borges no constituyen un buen ejemplo de la poesía, según el entendimento platónico de ese término. Por ende, el argumento del ensayo parece ser un mero ignoratio elenchi."

\footnotetext{
${ }^{32}$ Le debo esa frase evocativa "la voz de la poesía" a Michael Oakeshott (1962, pp. 197247).
} 
Respuesta: Si el poema de Borges no es poesía en el sentido de Platón, sí lo es, sin embargo, según nuestro entendimiento de la palabra; y puede ser que este hecho tenga implicaciones interesantes y sorprendentes. Aquí sólo destacaré una de ellas: la de que la frontera entre la poesía (en nuestro sentido) y la filosofía (en el sentido platónico) pueda ser bastante más flexible y fluida de lo que algunos de nosotros hemos pensado. Pero ¿por qué digo esto?

He defendido la tesis de que "Things That Might Have Been" nos deprende de las realidades de la vida cotidiana; el poema nos las presenta como cosas radicalmente contingentes y, por lo tanto, menos sólidas o estables de lo que nosotros, en un estado de inocencia metafísica, habíamos reconocido. Ahora bien, si esta interpretación del poema tiene validez, entonces podríamos sostener que el poema de Borges efectivamente inicia la tarea de la filosofía, como Platón entiende la filosofía, pues, según el Mito de la Caverna en la República, la primera etapa de la filosofía esencialmente involucra la adopción de una actitud escéptica frente a las apariencias comunes y corrientes; es decir, un rechazo solemne por aceptarlas como algo dado o como incuestionables y absolutas, un rechazo a darlas por hecho.

Objeción 4: "Decir que la poesía es un preludio a la filosofía es sugerir que la poesía funciona meramente como una introducción a lo que es realmente importante o esencial (es decir, la reflexión filosófica). Por lo tanto, ¿̇no refleja esa metáfora precisamente el prejuicio cuasiplatónico contra la poesía que este ensayo quiere combatir?"

Respuesta: Aquí quiero decir dos cosas. En primer lugar, hay que reconocer abiertamente que la metáfora del preludio tiene, como todas las metáforas, sus limitaciones. Pero, aunque entiendo por qué alguien podría opinar que mi metáfora expresa la subordinación humillante de la poesía ante la filosofía, se debe subrayar que es posible entenderla de otra manera. Preguntémonos: ¿qué hace un preludio en una ópera? Anticipa lo que vendrá, presentando los principales temas y motivos musicales en una forma dinámica, condensada y unida. Dadas estas propiedades, no debe ser nada sorprendente que a veces - y la experiencia es tan común como lamentable- una ópera resulta ser una decepción exasperante; nos ofrece un tratamiento largo, lento, repetitivo y aburrido de estos temas tan cautivadores y fascinantes introducidos por el preludio con más economía, brío y brillantez. Y lo mismo que pasa a veces con la ópera puede pasar con la filosofía.

Así es que la metáfora del preludio en sí no nos obliga a otorgarle a la poesía un estatus categóricamente inferior; sin embargo, y éste es mi segundo comentario, quizás sería mejor usar otra metáfora, en la cual la falta de una jeraquía necesaria o de una prioridad absoluta se pudiese ver más fácilmente; podríamos decir, por ejemplo, que la poesía es un camino 
a la filosofía. Cabe destacar la falta deseada de asimetría aquí: decir que $X$ es un camino a $Y$ obviamente no es incompatible con la posibilidad de que $Y$ sea un camino que nos conduzca a $X$.

\section{En lugar de una conclusión}

And yet, and yet... Me puedo imaginar un comentario sobre "Things That Might Have Been" escrito con una mezcla inimitable de elocuencia, erudición, ingenio y agradable sofistería. Entre sus tesis principales, seguramente se encontrarían algunas, si bien no todas, de las siguientes aseveraciones:

(a) que el poema de Borges no es meramente un preludio a la filosofía, sino una obra de filosofía en sí;

(b) que "Things That Might Have Been" es una realización del dictum de Wittgenstein de que la filosofía debe escribirse como una composición poética (Wittgenstein 1980, 24e);

(c) que un borrador de "Things That Might Have Been" se encontró entre los papeles de Pierre Menard —un hecho curioso, ignorado por Borges en su ensayo dedicado a ese autor-;33

(d) que el poema de Borges - y, de hecho, la poesía en general— sólo tiene valor como una manera de acercarse a la filosofía;

(e) que el poema de Borges - $y$, de hecho, la poesía en general— sólo tiene valor como una manera de escapar o trascender la filosofía, disciplina que tiende a matar el asombro que la parió;

(f) que la filosofía no puede aprender nada de la poesía (aunque lo contrario no es cierto);

(g) que la poesía no puede aprender nada de la filosofía (aunque lo contrario no es cierto);

(h) que la manera en la que Borges maneja el tema de la contingencia establece vínculos sugerentes entre su obra y las de Hume, Sartre y Wittgenstein, quienes ahora se pueden ver como precursores de Borges; ${ }^{34}$

(i) que (pace Platón) no existe una distinción entre la poesía y la filosofía;

33 Véase "Pierre Menard, autor del Quijote" (OC I, pp. 444-450).

${ }^{34}$ Véase "Kafka y sus precursores" (OC II, pp. 88-90). 
(j) que la postura de David Lewis sobre la metafísica de los mundos posibles, específicamente su realismo modal, ha convertido a Borges en uno de los precursores ilustres de Lewis; ${ }^{35}$

... etcétera. Yo puedo, repito, imaginar un tal comentario; y sin duda usted, mon semblable, puede imaginarlo también. Y si le gustaría leerlo - ya sea con calma o con rapidez-, yo sólo podría devolverle el eco de su deseo, que por supuesto comparto. Pero, hasta donde yo sé, la cosa no existe; y de haberla leído, lo que usted acaba de leer no se hubiera escrito y - es absurdo, no lo negaré- a la Patagonia no hubiera venido un tal canadiense con un acento medio mexicano. ${ }^{36}$

\section{BIBLIOGRAFÍA}

Berkeley, G., 1998 (1710), A Treatise Concerning the Principles of Human Knowledge, ed. J. Dancy, Oxford University Press, Oxford.

Borges, J.L., 1996, Obras completas, Emecé Editores, México, 4 vols.

Bradbury, M., 1992, Doctor Criminale, Picador, Londres.

Burgin, R., 1974, Conversaciones con Jorge Luis Borges, trad. M. Coronado, Taurus, Madrid.

Carlyle, T., 1987 (1834), Sartor Resartus, Oxford University Press, Oxford.

Chesterton, G.K., 1957 (1908), Orthodoxy, Bodley Head, Londres.

_ , 1911, The Innocence of Father Brown, John Lane, Nueva York.

Eco, U., 1986, Travels in Hyperreality: Essays, trad. W. Weaver, Harcourt Brace Jovanovich, Nueva York.

Green J., 1976, Memories of Evil Days, University of Virginia Press, Charlottesville.

— 1942 , Memories of Happy Days, Harper, Nueva York.

Kermode, F., 1989, An Appetite for Poetry, Harvard University Press, Cambridge, Mass.

Lewis, D., 1986, On The Plurality of Worlds, Basil Blackwell, Oxford.

— 1973, Counterfactuals, Harvard University Press, Cambridge, Mass.

McDermid, D., 2004, "Is Davidson's Epistemology Coherent?", Grazer Philosophische Studien, no. 67, pp. 101-130.

— 2003 , "The World as Representation: Schopenhauer's Arguments for Transcendental Idealism", British Journal for the History of Philosophy, vol. 11, no. 1, pp. 57-87.

— 2002, "Schopenhauer as Epistemologist: A Kantian Against Kant", International Philosophical Quarterly, vol. 42, no. 2, pp. 209-229.

_ 2000 , "Does Epistemology Rest on a Mistake? Understanding Rorty on Scepticism", Crítica, vol. 32, no. 96, pp. 3-42.

Nabokov, V., 2002, The Stories of Vladimir Nabokov, Vintage, Nueva York.

Nagel, T., 1986, The View From Nowhere, Oxford University Press, Nueva York.

\footnotetext{
${ }^{35}$ Véanse Lewis 1973 y 1986.

${ }^{36}$ Agradezco a Carlos Pereda, a un árbitro anónimo y a aquellos que me escucharon en el Séptimo Coloquio Internacional Bariloche de Filosofía (septiembre de 2004).
} 
Nuño Montes, J.A., 1986, La filosofía de Borges, Fondo de Cultura Económica, México.

Oakeshott, M., 1962, Rationalism in Politics, Methuen, Londres.

Pascal, B., 1964, Pensées, Éditions Garnier Frères, París.

Pater, W., 1986 (1873), The Renaisance, Oxford University Press, Oxford.

Pereda, C., 1998, Sueños de vagabundos: un ensayo sobre filosofía, moral y literatura, Visor, Madrid.

Platón, 1961, The Collected Dialogues, E. Hamilton y H. Cairns (comps.), Princeton University Press, Princeton.

Rodríguez Monegal, E., 1978, Jorge Luis Borges: A Literary Biography, E.P. Dutton, Nueva York.

Rorty, R., 1989, Contingency, Irony, Solidarity, Cambridge University Press, Cambridge.

Rossi, A., 1986, Manual del distraído, Fondo de Cultura Económica, México.

Sarlo, B., 1995, Borges, un escritor en las orillas, Ariel, Buenos Aires.

Schopenhauer, A., 1960-1965, Sämtliche Werke, W. Von Löhneysen (comp.), CottaInsel, Stuttgart/Fráncfort del Meno, 5 vols.

Shakespeare, W., 1993, The Yale Shakespeare, ed. W. Cross y T. Brooke, Barnes and Noble, Nueva York.

Strawson, P.F, 1985, Skepticism and Naturalism: Some Varieties, Columbia University Press, Nueva York.

Vaccaro, A., 1996, Georgie (1899-1930): Una vida de Jorge Luis Borges, Proa/Alberto Casares, Buenos Aires.

Wittgenstein, L., 1980, Culture and Value, trad. P. Winch, G.H. von Wright (comp.), Basil Blackwell, Oxford.

— 1969, On Certainty, trad. D. Paul y G.E.M. Anscombe, Harper, Nueva York.

Recibido el 4 de agosto de 2004; aceptado el 1 de febrero de 2005. 